\title{
Modeling and methodology for calculating the strength of a man-made bottom in a system with self-destruction of ore for ecologically safe mining
}

\author{
Evgeny Fedorov ${ }^{1, *}$, Dosanbay Bekbergenov ${ }^{2}$ and Gulnar Jangulova ${ }^{3}$ \\ ${ }^{1}$ Institute for the Problems of Integrated Subsoil Development, 111020, Moscow, Russia \\ ${ }^{2}$ Institute of Mining named after D.A. Kunaev, 050040, Almaty, Kazakhstan \\ ${ }^{3}$ Al-Farabi Kazakh National University, 050046, Almaty, Kazakhstan
}

\begin{abstract}
The article discusses the features of technological solutions in the development of chromite deposits at great depths in difficult mining and geological conditions. For a system with self-destruction of ore, as well as for other similar systems, the weakest point in mining is the design of the block bottom, especially for the lower horizons, where the geomechanical situation deteriorates significantly, it becomes necessary to use more powerful supports or to erect artificial bottoms that can withstand acting loads exceeding the bearing capacity of metal supports of various modifications. The most promising solution in the conditions of development of fractured massifs is the geotechnology of creating an man-made bottom at the zone of extraction and delivery of ore mass, in the areas of conjugation overstrett and interstrett pillars, reinforced with multi-support reinforced concrete platforms, as a bearing structural element of the mining system with self-destruction of ore, which can withstand extremely high rock pressure. The article presents the results of calculating the strength of an artificial bottom in a system with selfdestruction of ore using numerical 3D modeling.

Key words: geomechanics, development system, rock pressure, rock mass, chromite mining, modeling technique, block bottom.
\end{abstract}

\section{Introduction}

With the transition of mining operations to the lower horizons for the «Ten Years of Independence of Kazakhstan» mine, the scouring stoping will be carried out under the destructed massif. At the initial stage of scouring works, the load on the support of mine workings will be formed due to the height of the layer of the destructed mass of the ore massif. With the development of mining operations, in the process of self-destruction, the layer height will increase and at a certain moment the overlying horizon will merge with the collapsed massif, which will lead to a significant increase in pressure on the bottom of the block $[1-3,13]$.

As practice has shown, a single-layer fastening with a sufficiently dense installation of frames does not always turn out to be reliable and stable. A large number of workings (up to $60-70 \%$ ), mainly scraping strett, fail without having served their full service life. It is

*Corresponding author: evfedorov58@gmail.com 
necessary to re-fasten and restore the damaged lining, which inevitably leads to significant material and financial costs, and as a result, to an increase in the cost of mined ore and, importantly, to a decrease in the safety of mining operations and disruption of the rhythm of the main technological processes. For the lower horizons, where the geomechanical situation is significantly deteriorating, the question arises about the need to use more powerful supports or the construction of man-made bottoms that can withstand the current loads that exceed the bearing capacity of metal supports of various modifications and construction schemes [4-6].

Concerning, we have proposed technological solutions for the construction of an artificial bottom, with 3D modeling and calculation of the strength of an artificial bottom in a system with self-collapse of ore for environmentally safe development of the lower horizons of the Don chromite deposit.

\section{Materials and methods}

The volumetric analysis model was built in the automatic design system AutoCAD and imported into the ANSYS Workbench environment using the compatibility of CAD / CAM / CAE systems through the export and import of volumetricsolids in the ACIS SAT file format.

The computational model consists of outlet workings, their sizes, which are shown in Figure $1 \mathrm{a}$, the general scheme is shown in Figure $1 \mathrm{~b}$.
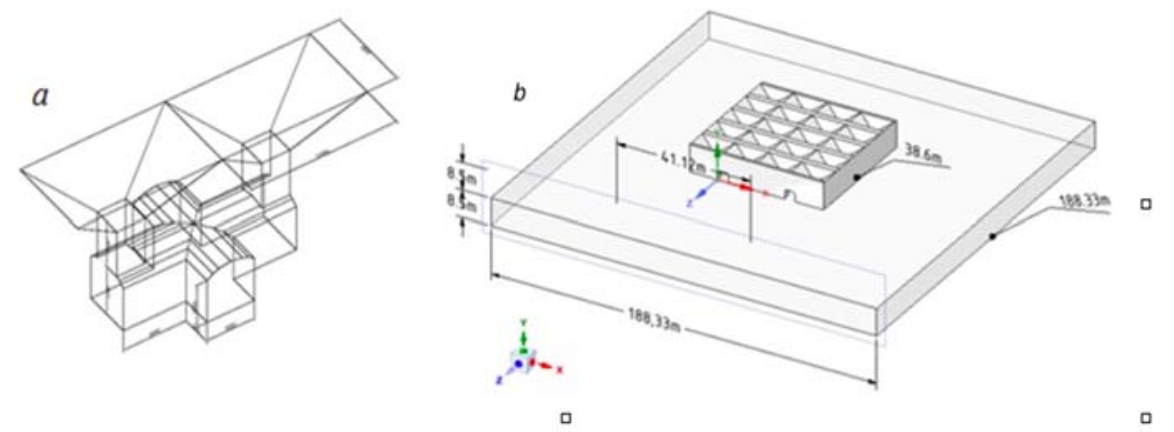

Fig. 1. Volumetric calculation model of the block bottom

The design scheme is presented in the form of a block with the dimensions of the scraping strett of $4.46 \times 3 \mathrm{~m}$ along the height of the vaulting part, the dimensions of the funnel are $10.3 \times 6$ meters. Chromite rocks with averaged mechanical characteristics of the rock and lining materials were selected as a rock mass (Table 1). The design diagram of the manmade bottom of the block in a system with self-destruction of ore is a monolithic reinforced concrete structure, the strength of which is equal to the strength of concrete of class B25. The loads are specified for depths of 560, 720, $960 \mathrm{~m}$, the values of which are given in Table 2 .

Table 1. Average mechanical characteristics of rock and lining material.

\begin{tabular}{|l|c|l|l|c|c|c|c|c|c|}
\hline $\begin{array}{l}\text { Solid and } \\
\text { material }\end{array}$ & $\begin{array}{l}\text { Volume } \\
\text { weight, } \\
\mathrm{gs} / \mathrm{cm}^{3}\end{array}$ & $\begin{array}{l}\text { Elastic } \\
\text { modulus } \\
\mathrm{E}^{*} 10^{-} \\
{ }^{\mathrm{kgs} / \mathrm{cm}^{2}} \\
(\mathrm{GPa})\end{array}$ & $\begin{array}{l}\text { Poiss } \\
\text { on's } \\
\text { ratio } v\end{array}$ & $\begin{array}{l}\text { Compre } \\
\text { ssive } \\
\text { strength } \\
\mathrm{kgs} / \mathrm{cm}^{2}\end{array}$ & $\begin{array}{l}\text { Ultimate } \\
\text { tensile } \\
\text { strength, } \\
\mathrm{kgs} / \mathrm{cm}^{2}\end{array}$ & $\begin{array}{l}\text { Shear } \\
\text { streng } \\
\text { thkgs/ } \\
\mathrm{cm}^{2}\end{array}$ & $\begin{array}{l}\text { Streng } \\
\text { thcoef } \\
\text { ficient } \\
f\end{array}$ & $\begin{array}{l}\text { Internal } \\
\text { friction } \\
\text { angle } \\
\text { degree }\end{array}$ & $\begin{array}{l}\text { Сцеп } \\
\text { ление } \\
\mathrm{kgs} / \mathrm{c} \\
\mathrm{m}^{2}\end{array}$ \\
\hline $\begin{array}{l}\text { Chromite } \\
\text { rocks }\end{array}$ & 2,7 & 65 & 0,22 & 144 & 10 & 26 & 6,1 & 36 & 48 \\
\hline Concrete B25 & 2,5 & 300 & 0,2 & 224 & & & & & \\
\hline
\end{tabular}


Table 2. Specified loads for the depth of the horizons

\begin{tabular}{|l|c|c|c|c|}
\hline № & Horizon depth $(\mathrm{m})$ & $\begin{array}{c}\text { Pressure (load) unit } \\
\text { ts } / \mathrm{m}^{2}\end{array}$ & $\begin{array}{c}\text { Pressure (load) units } \\
\text { MPa }\end{array}$ & Coordinate system \\
\hline 1 & 560 & 2016 & 19,770 & axis Y \\
\hline 2 & 720 & 2592 & 25,419 & axis Y \\
\hline 3 & 960 & 3456 & 33,892 & axis Y \\
\hline
\end{tabular}

The design scheme consists of 27,000 nodes of 13,080 finite elements, based on the results of calculations, an increase in the values of deformations, stresses and displacements of these nodes at great depths was determined. A similar technique for calculating the stress-strain state of an underworked rock mass was used in $[14,15]$.

The gradual destruction of reinforced concrete outlet funnels occurs under continuous intense exposure to loads, which leads to additional dilution. The intensity of the ore dilution process depends on the strength of reinforced concrete structures, the results of total deformations of which at depths of 560, 720, 960 meters are shown in Figures 2-4.

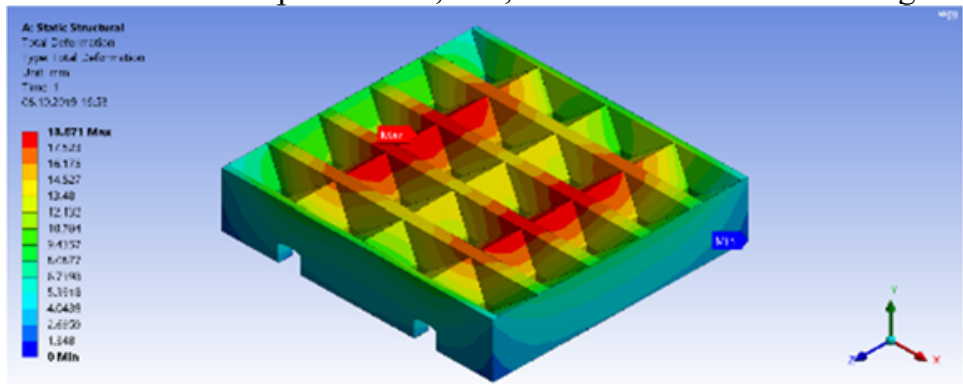

Fig. 2. Full deformation value ata man-made bottom at a depth of $560 \mathrm{~m}$

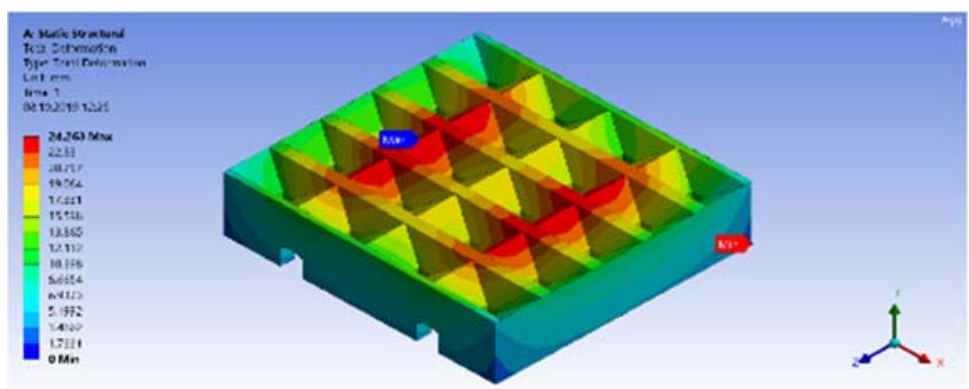

Fig. 3. Full deformation value at aman-made bottom at a depth of $720 \mathrm{~m}$

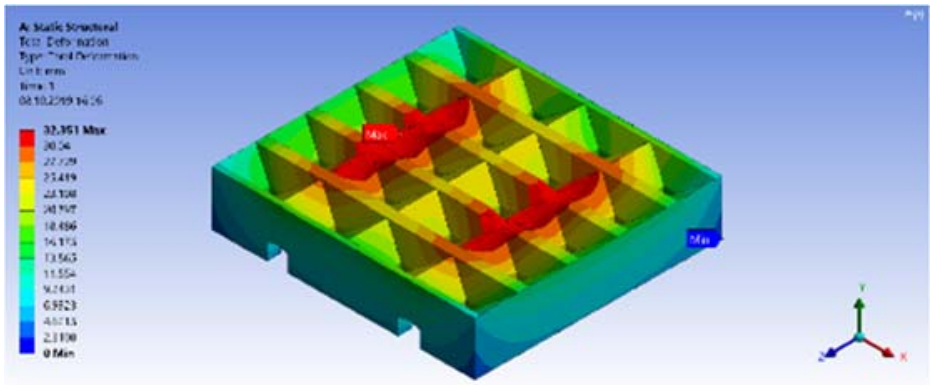

Fig. 4. Total deformation value at aman-made bottom at a depth of $960 \mathrm{~m}$ 
Based on the simulation results, a graph of the dependence of deformations on the depth of the man-made bottom was obtained (Figure 5).

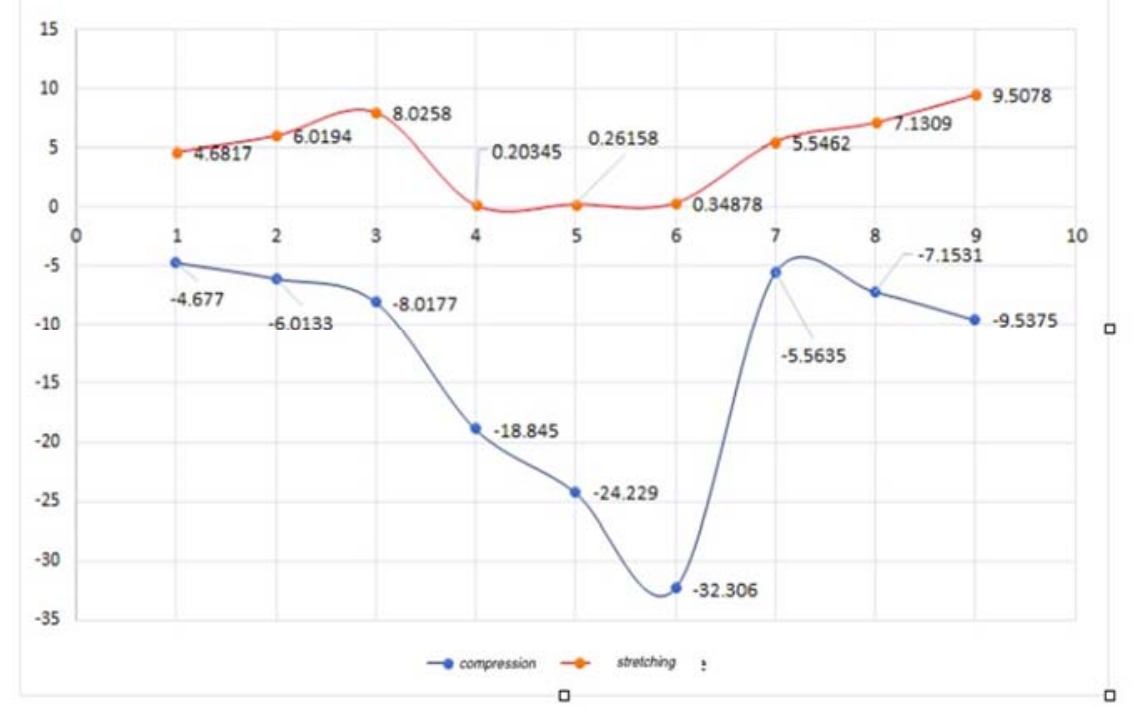

Fig. 5. The values of the results of deformations in millimeters in all directions $\mathrm{X}, \mathrm{Y}, \mathrm{Z}$ for horizons 560; $-720 ;-960 \mathrm{~m}$

Based on the results of the calculations, an analysis was made of the effect of the loads on the nodes of reinforced concrete structures of the man-made bottom (MMB), which are subject to deformation at the junctions of the funnels and the lower part of the overstratt pillar located above the scraping strett. The man-made bottom design developed and proposed by us can provide sufficient reliability, stability and operability of mine workings.

Methodology and example of calculating the strength of the proposed MMB. The technology of ore self-destruction by creating an MMB block with a multi-support reinforced concrete platform is a structure consisting of vertical reinforced concrete elongated pillars, located in the pillar between the scraping stretts, up to $8 \mathrm{~m}$ high with parameters in terms of $5 \mathrm{~m}$ wide [7-9].

An element of the proposed design of the MMB block is a horizontal reinforced concrete over strett pillar, passing directly above the roof and along the entire length of the loop (instead of the ore overhead pillar), which is connected to inter-transverse horizontal reinforced concrete beams connected to the upper part between vertical rectangular elongated reinforced concrete pillars-supports.

The calculation of the strength of the man-made bottom (MMB) includes:

- determination of the bearing capacity;

- determination of the load on reinforced concrete pillars, supports, horizontal reinforced concrete beam and horizontal overhead reinforced concrete pillar;

-calculation of the safety factor $k_{s . f .}$.

The optimal parameters of the bearing elements of the structure of the proposed MMB for the base of the block with self-destruction technology are:

- vertical square reinforced concrete pillars, vertical rectangular elongated reinforced concrete supports (with design parameters - the height of the supports is from 6 to $8 \mathrm{~m}$ );

- vertical rectangular elongated reinforced concrete barrier supports in the cross-road pillar (with design parameters - $5 \mathrm{~m}$ ); 
- horizontal reinforced concrete beams located in length and across from the workings of the scraping strett (with the parameters of the beam thickness - $5 \mathrm{~m}$ ) with a mesh connection of the upper part;

- horizontal overhead reinforced concrete beams in the form of a prismatic pillar, located above the roof and along the entire length of the drift by scraping connecting the upper part of an intertransverse horizontal reinforced concrete beam with the upper part between vertical rectangular elongated reinforced concrete pillars with supports located in the crossroad pillar.

The calculation of the bearing capacity of a vertical reinforced concrete pillar-support of a rectangular shape is carried out according to the method of calculating an inter-chamber barrier pillar with a chamber-pillar development system.

\section{Results and Discussion}

The performed calculations of the strength of a vertical square reinforced concrete pillarsupport located in the interstrett pillar of the scraping road allowed to determine the optimal parameters for the proposed design of man-made multi-support platform bottoms for underground mining with self-destruction technology [10-12].

\subsection{Mining and geological conditions and geometrical parameters:}

1. Parameters of a vertical square reinforced concrete pillar-support $-2.8 \mathrm{~m}$ wide and $2.8 \mathrm{~m}$ long;

2. Height of a vertical square reinforced concrete pillar-support - from 5 to $8 \mathrm{~m}$;

3. The distance along the axis between the scraping stretts in the panel is $12 \mathrm{~m}$;

4. The distance along the axis between the workings of niches along the scraping strett is $6 \mathrm{~m}$;

5. Thickness or transverse height of horizontal reinforced concrete beams $\approx 5.0 \mathrm{~m}$;

6. Width of horizontal reinforced concrete beams $-2.8 \mathrm{~m}$;

7. Length of horizontal reinforced concrete beams along and across the scraping strett : $3.2 \mathrm{~m}$ and $9.2 \mathrm{~m}$, respectively;

8. The length of the horizontal overhead reinforced concrete beams located directly above the roof of the scraping strett is $3.2 \mathrm{~m}$, thickness from the roof of the loop to the upper contour of the horizontal reinforced concrete slabs;

9. The thickness of the overlying strata is $\mathrm{H}=880 \mathrm{~m}$.

10. Width of the tape panel $\mathrm{L}=30 \mathrm{~m}$;

11. The angle of inclination of the deposit is up to $10-15^{\circ}$;

12. Volumetric weight of rocks of overlying strata $\gamma=2,5 \mathrm{t} / \mathrm{m}^{3}$;

13. The height of the vault of the desctructed chamber is 80 meters high, $\mathrm{h}_{\text {vault of dest-on }} \approx$ $200 \mathrm{~m}$;

14. Strength of ore sandstone rocks $\delta_{\text {comp }}-20000 \mathrm{t} / \mathrm{m}^{2}(200 \mathrm{MPa})[16]$ :

15. Compressive strength of concrete $-\sigma_{\text {con. comp. }}=15,0 \div 30,0 \mathrm{MPa}\left(150 \div 300 \mathrm{~kg} / \mathrm{cm}^{2}\right.$ or $1500 \div 3000 \mathrm{t} / \mathrm{m}^{2}$ ). According to the project, the proposed platform is erected from a reinforced concrete structure, therefore, for the design index of the strength of reinforced concrete, we take the compressive strength of concrete equal to $\sigma_{\text {com. reinf.con. }}=150$ MPaor $\left(\sigma_{\text {com. reinf.con. }}=15000 \mathrm{t} / \mathrm{m}^{2}\right)$. 


\subsection{Determination of the load on a vertical elongated rectangular reinforced concrete pillar-support.}

1. Bearing capacity of a vertical reinforced concrete pillar-support:

$$
N_{c}=\sigma_{\text {con. comp. }} \cdot F i \cdot k_{f} \cdot k_{G} \cdot k_{\alpha}=700 \times 18,6 \cdot \sqrt{\frac{2,8}{6,0}} \cdot 0,75 \cdot 1=88200 \mathrm{t} \text {. }
$$

2. Load on a vertical reinforced concrete pillar-support:

$Q=K_{n} \cdot\left\{\left(\gamma_{r} \cdot L_{1} \cdot L_{2} \cdot h_{\kappa}\right)+\left(\gamma_{r} \cdot L_{1} \cdot L_{2} H\right)\right\}=1\{(3,6 \cdot 12 \cdot 6 \cdot 80)+(2,6 \cdot 12 \cdot 6 \cdot 200)\}=$ $20736+37440=58176 \mathrm{t}$.

3. Safety factor coefficient of the vertical reinforced concrete pillar-support:

$n_{r}=N_{c} / Q=88200: 58176=1,51$

\subsection{Determination of the load on the horizontal beams located along the overstrack pillar and relative to the scraper strack.}

1. Bearing capacity of horizontal reinforced concrete beams, transversely connected above the stracks of scraping between segments of workings of niches with the upper part of vertical reinforced concrete pillars, erected in the interstrack pillar:

$$
N_{\text {tape interchamber pillar }}=20000 \cdot 15 \cdot \sqrt{\frac{5,0}{10}} \cdot 0,75=159750 \mathrm{t} \text {. }
$$

2. Load on interchamber pillar (tape): $\quad Q=80 \cdot 500 \cdot 2,5=100000 \mathrm{t}$.

3. Safety factor coiffient ofinterchamber pillar (tape): $n_{\text {tape interchamber pillar }}=\frac{159750}{10000}=1,6$

According to the calculations of the strength of the reinforced concrete pillar-support with a height of $h_{\text {sup }}=7 \div 9 \mathrm{~m}$ for the proposed multi-support reinforced concrete bottom structure, the safety factor was $n=1.51$ with the required value at $n \geq 1.4$.

\section{Conclusion}

The developed methodological scheme is the starting point for the development and substantiation of the parameters of the mining construction of the man-made bottom of the block by the system with self-destruction of ore on the deep horizons of the "Ten Years of Independence of Kakhastan" mines.

Based on the foregoing, it can be argued that the man-made bottom of the block with a stable support reinforced concrete platform will provide the necessary conditions for safe and efficient mining of ores in difficult mining conditions at the deep horizons of Don chromite mines using the technology with self-destruction of ore.

\section{References}

1 L. Zherebko, L. Shamganova, G. Jangulova, Kh. Kassymkanova, B. Bektur, 16thInternational multidisciplinary scientific geoconference. Exploration and mining. Mineral processing. Sgem 2016, 775-780 (2016)

2 D.K. Bekbergenov, G.K. Jangulova, A.N. Kabdeshev, A.A. Toktarov, International Scientific and Technical Conference "Problems and Ways of Innovative Development of the Mining and Metallurgical Industry "November 27-29, 2014, Tashkent, 112-116 (2014) 
3 Studying Engineering and Geological Conditions of Development of the Southern Part of the Almaz-Zhemchuzhina Chromite Ore Deposit. Report on Scientific and Research Work (VIOGEM, Belgorod, 1979)

4 Z.A. Terpogosov, Base blocks and mechanization of ore production (M., "Nedra", 1977)

5 Studying Engineering and Geological Conditions of Development of the Southern Part of the Almaz-Zhemchuzhina Chromite Ore Deposit. Report on Scientific and Research Work (VIOGEM, Belgorod, 1979)

6 Development and Implementation of Measures to Improve Mining Technology at the Molodezhnaya, Central and Glubokaya Mines of the Don Mining and Processing Plant based on Geological and Engineering Zoning with Due Account for the Structure and Secondary Changes in Rocks. Report on Scientific and Research Work (VIOGEM, Belgorod, 1990)

7 Examination of the Strength and Deformation Properties of the Rock Mass for Production Levels of the Central Mine. Report on Scientific and Research Work (progress report) (Mining Institute of the Academy of Science of the KazSSR, Alma-Ata, 1990)

8 Examination of the Strength and Deformation Properties of the Rock Mass for Production Levels of the Central Mine. Report on Scientific and Research Work (progress report) (Mining Institute of the Academy of Science of the KazSSR, Alma-Ata, 1991)

9 Development of New Highly Efficient and Safe Technologies for Underground Mining of Ores of Fer-roalloy Raw Materials at Great Depths. Stage: "Development of Operating Procedure..."//Report on Research, topic \# 15 (Mining Institute after D.A. Kunayev, Almaty, 2005)

10 Yu.I. Iakovlev, L.N. Zherebko, G.K. Jangulova, L.M. Pivovarova, Scientific and Technical Support for Mining Production. Proceedings of the Mining Institute after D.A. Kunayev, 69, 67-70 (2005)

11 Engineering and Geological Procedure for Stracking a Man Shaft at the "Central" Mine of the Don Mining and Processing Plant Within -384.5-428.5 m. (VIOGEM, Belgorod, 1988)

12 T.M. Ahanov, G.A. Prokushev, Mining Journal of Kazakhstan, 1, 12-17 (2010)

13. K.N. Trubetskoy, D.R. Kaplunov, M.V. Ryl'nikova, D.N. Radchenko etc. Development of Resource-saving and Resource-reproducing Geotechnologies for Integrated Development of Mineral Deposits (M., IPKON RAS, 2012)

14. I.V. Miletenko, N.A. Miletenko, V.N. Odintsev, J.D. Baigurin, J.S. Abaideldinov, B.B. Imansakipova, Mine Surveying and Subsurface Use (Marksheyderia i Nedrapolsovanie), 6 (62), 42-49 (2012)

15. V.N. Odintsev, N. A. Miletenko, E.V. Fedorov A new methodological approach to solving problems in environmental geomechanics and safety. In The Scientific Foundations of Mining Safety (M.: IPKON RAS, 2018) 